\title{
Methodological analysis of fertilization rate in the bluehead wrasse Thalassoma bifasciatum: pair versus group spawns
}

\author{
A. Marconato ${ }^{1, *}$, D. Y. Shapiro ${ }^{2, * *}$, C. W. Petersen ${ }^{3}$, R. R. Warner ${ }^{4}$, T. Yoshikawa ${ }^{5}$ \\ ${ }^{1}$ Department of Biology, University of Padova, Viale Trieste 75, I-35121 Padova, Italy \\ ${ }^{2}$ Department of Biology, Eastern Michigan University, Ypsilanti, Michigan 48197, USA \\ ${ }^{3}$ College of the Atlantic, Bar Harbor, Maine 04609, USA \\ ${ }^{4}$ Department of Biological Sciences, University of California, Santa Barbara, California 93016, USA \\ ${ }^{5}$ Department of Zoology, University of Hawaii, Honolulu, Hawaii 96822, USA
}

\begin{abstract}
Accurate measurement of fertilization rate (FR) is essential for reproductive studies of pelagically spawning marine organisms. We compared the reliability of 3 methods of collecting eggs for estimates of FR in the coral reef fish Thalassoma bifasciatum: collecting in hand-held nets $30 \mathrm{~s}$ after spawning or in plastic bags 3 to $4 \mathrm{~s}$ ('early bag') or $30 \mathrm{~s}$ ('late bag') after spawning. FRs were significantly and consistently lower in eggs collected by net than in eggs collected in early or late bags. FRs were consistently highest in late bags. In field experiments, netted samples contained higher proportions of negatively buoyant, unfertilized eggs and the negative effects of the net declined with increasing time from initial exposure of eggs to seawater and sperm. Thus, the net appeared to interfere mechanically with the fertilization process. FRs were not higher in smaller than in larger bags, as would have been expected if bags artificially prolonged high average sperm concentration around eggs. The average concentration of sperm in a bag containing twice the largest number of sperm ever collected in any spawn was less than the minimum sperm concentration needed to initiate fertilization. Thus, the difference in FR between netted and bagged samples was not the result of prolonged maintenance of an artificially high average sperm concentration in the bag. Using bag collection techniques, we compared FRs for pair and group spawns. Mean FRs ranged from 86.6 to $99.5 \%$, with analyzable variance. Contrary to the results of a previous study using netted samples, group spawns had significantly higher FRs than pair spawns using early bag samples. Female mating tactics ought to be influenced evolutionarily by this difference between pair and group spawns.
\end{abstract}

KEY WORDS: Fertilization rates - Methods · Pair spawns - Group spawns - Reef fish

\section{INTRODUCTION}

In the marine environment, female reproductive success in pelagically spawning species depends in part on the proportion of the female's egg clutch that is successfully fertilized after gametes have been released freely into the water column. Among sessile and quasisessile invertebrates, such as sea urchins, this proportion, called the fertilization rate $(F R)$, may fall well

\footnotetext{
- Deceased

- Addressee for correspondence

E-mail: douglas.shapiro@emich.edu
}

below $100 \%$ when the sexes are physically separated by as little as $20 \mathrm{~cm}$ at the moment of gamete release (Pennington 1985, Levitan 1991, 1993, Levitan et al. 1991, Lasker \& Stewart 1993). Thus, in spite of the release of large numbers of sperm by males, the rapid diffusion of eggs and sperm by water movement in the time required for sperm to reach the eggs reduces the FR substantially.

Pelagically spawning marine fishes, with relatively narrow bodies and the ability to swim rapidly, can closely appose male and female gonopores at the apex of spawning rushes, when gametes are released. Consequently, gametes are diluted to a lesser degree 
than in invertebrates and FRs may be higher in these fishes.

In recent studies of 2 coral reef fishes, FRs were measured in eggs swept from the water column in a handheld brine-shrimp net $30 \mathrm{~s}$ after spawning (Petersen 1991, Petersen et al. 1992). FRs were variable and substantially lower than $100 \%$ during spawns involving pairs of 1 male and 1 female. In one of these species, Thalassoma bifasciatum, there are 2 types of males, one type spawning in single, male-female pairs and the other type spawning primarily in groups (Reinboth 1973, Warner et al. 1975). In group spawns, 5 to 20 males each release sperm together with the egg release of a single female, resulting, on average, in the release of 50 times as many sperm as in pair spawns (Shapiro et al. 1994). FRs among group spawns, however, were reported to be no higher on average than in pair spawns (Petersen et al. 1992).

Using a different technique for collecting eggs, in a large plastic bag, Yoshikawa (1992) obtained preliminary evidence that FRs in Thalassoma bifasciatum were less variable than reported by Petersen et al. (1992) and were significantly higher in group spawns than in pair spawns. Since many species of coral reef fish employ both pair and group spawning (Thresher 1984), and since, all else being equal, natural selection is expected to favor females spawning in a mode that provides them with the highest FR, the issue of whether females can obtain higher FRs in group than in pair spawns is critical for an evolutionary analysis of a mating system.

Accurate measurement of FR will be important for other issues as well. Of 49 families of reef fishes, species in 36 families spawn pelagically, but the evolutionary costs and benefits that have led to pelagic spawning remain unclear (Thresher 1984). Behavioral and morphological adaptations that improve the efficiency of pelagic spawning, thereby enhancing the benefitto-cost ratio, will need to be evaluated with measures of reproductive success, including FR. Accurate measurement of FR is a starting point for such studies.

The purposes of this study, then, were to compare techniques used in previous studies of FR, collecting eggs in a hand-held net and in a plastic collecting bag, to determine the strengths and weaknesses of each technique, and to re-examine FRs in pair-and groupspawning bluehead wrasse.

\section{METHODS}

Study species and study sites. Thalassoma bifasciatum is a small (up to $15.2 \mathrm{~cm}$ total length; Randall 1968) coral reef fish ubiquitous throughout the Caribbean. Juveniles pass through an initial, ovarian phase
(Shapiro \& Rasotto 1993) prior to developing either into functional females or primary males, both of which have identical coloration (called initial-phase or IP coloration; Warner et al. 1975). The largest individuals in a local population are strikingly colored terminalphase (TP) males. These TP males may be derived by sex change from females (secondary males) or by color and behavioral change from primary males (Warner \& Robertson 1978). Pair spawning involves 1 TP male and 1 female rushing 0.3 to $1.5 \mathrm{~m}$ upward in the water above a particular spawning site and releasing gametes at the apex of the spawning rush (Reinboth 1973. Warner et al. 1975). Pair spawns may be 'streaked' by an IP male that joins the pair at the apex of the spawning rush. Pair-spawning males control the number of sperm released in successive spawns during daily 1.5 to $2.5 \mathrm{~h}$ mating periods (Shapiro et al. 1994). The number of sperm released by a male varies with the body size and clutch size of the female (Shapiro et al. 1994; cf. Marconato \& Shapiro 1996, for similar results in another species). Group spawning involves one female and up to 20 IP males in a single spawning rush. The total number of sperm released in group spawns also increases with the number of eggs released by the female (Shapiro et al. 1994). On average, group-spawning males each release 6 times as many sperm as do pair-spawning males (Shapiro et al. 1994). Eggs are generally 540 to $600 \mu \mathrm{m}$ in diameter (Feddern 1965, Petersen et al. 1992), are positively buoyant (Appeldoorn et al. 1988), and hatch in 20 to 24 h at 25 to $28^{\circ} \mathrm{C}$.

Work was done on the southwestern coast of Puerto Rico near La Parguera in March to September, 1992, and on the northeastern coast of St. Croix, U.S. Virgin Islands, east of Teague Bay, in May to October, 1993 and 1994. Collections were made on patch reefs of varying size in depths of 1 to $3 \mathrm{~m}$.

General approach. Fertilization rates were compared among field samples of pair and group spawns collected with net and bag. The net technique was identical to that employed in earlier studies (Petersen 1991, Petersen et al. 1992) and sampled eggs $30 \mathrm{~s}$ after spawning. We suspected that the bag technique would collect different numbers of eggs and possibly different percentages of fertilized eggs immediately after spawning than $30 \mathrm{~s}$ after spawning. Consequently, we compared FRs at both times with the bag. Since the net yielded significantly lower FRs than the bag (see 'Results'), we posed 2 alternative hypotheses to explain the difference: either (1) the net lowered FR by damaging eggs and/or otherwise interfering with the fertilization process; or (2) the bag raised FR by artificially maintaining a higher than normal concentration of sperm around eggs. We tested these hypotheses in 4 experiments. 
(1) We compared the proportion of unfertilized eggs that were non-buoyant between net and bag samples. Fish eggs may be damaged easily by a variety of forces, including shaking, mechanical pressure, air bubbles, water sprinkling, and wave action (Pommeranz 1974. Hemple 1979, Markle \& Waiwood 1985). Generally, eggs are most susceptible to damage prior to fertilization; damage is manifested by changes in the chorion, perivitelline membrane, and cytoplasmic properties. In pelagic eggs, positive buoyancy depends upon continued maintenance by the chorion and perivitelline membrane of a difference in density between the ovoplasm and surrounding seawater (Hemple 1979). Loss of integrity of those membranes would result in loss of positive buoyancy. In the bluehead wrasse, unfertilized eggs (those most sensitive to damage) lose positive buoyancy increasingly with time from first contact with seawater. For example, when we squeezed several ripe females in the field, and collected the emitted eggs in a bag, $2 \mathrm{~h}$ after collection the percentage of eggs lacking a perivitelline space and negatively buoyant (resting on the bottom of a petri dish rather than floating on the water's surface) was $13.6 \%$; by 4 h after collection the percentage had increased to $85 \%(\mathrm{n}=7$, paired $t$-test comparing $2 \mathrm{~h}$ with 4 h samples, $t=9.42, p<0.001$ ). We noticed what appeared to be consistent differences in the proportion of negatively buoyant, unfertilized eggs among samples collected with different techniques. Consequently, we examined this possibility formally, hypothesizing that if the net damaged eggs, the proportion of unfertilized eggs that sink should be higher at any time in net than in bag samples.

(2) If the net physically damages eggs, the effect should lessen with time after initial exposure of eggs to seawater and sperm, as eggs harden and fertilization advances (Pommeranz 1974, Markle \& Waiwood 1985). Hence, we compared the effect of netting on FR and the percentage of negatively buoyant unfertilized eggs at 2 time intervals after initial exposure of the egg to seawater and sperm.

(3) We compared FRs of eggs collected in large and small bags. If the bag artificially maintained high sperm concentration, FR ought to be lower in larger bags.

(4) We varied the concentration of sperm added experimentally to ripe eggs to reveal the minimum sperm concentration needed to initiate fertilization. We then compared that minimum with the concentration of sperm calculated to occur in the bag after the number of sperm released in normal pair and group spawns had dispersed fully in the bag. If the bag elevated FRs by artificially maintaining high sperm concentrations, then the final sperm concentration in the bag should at least exceed the minimum needed for fertilization to proceed.
Finally, employing both of our tested techniques, we compared FRs between pair and group spawns.

Egg collection methods. Snorkeillers positioned themselves 1 to $2 \mathrm{~m}$ from the site of spawning rushes. Two main techniques were used to collect eggs. First, immediately after spawning, the gamete cloud was marked with a small volume of fluorescein dye injected into the water from a squeeze bottle; $30 \mathrm{~s}$ later, a $15 \mathrm{~cm}$ brine-shrimp net (maximum mesh size approximately $100 \times 300 \mu \mathrm{m}$ ) was swept through the dye-marked water for $30 \mathrm{~s}$, as described by Petersen et al. (1992). Eggs were transferred immediately from the net into small plastic bags. This technique was called 'net'. When the number of eggs in a net sample was counted (see below), the sample was retained and used for data analysis only if the sample contained at least 20 eggs. Second, either 3 to $4 \mathrm{~s}$ ('early bag') or $30 \mathrm{~s}$ ('late bag') after spawning, the gamete cloud was enveloped within a plastic bag measuring $65 \times 60 \mathrm{~cm}(51 \mathrm{l})$ or $67 \times 60 \mathrm{~cm}$ (50.2 to 51.5 l, depend ing on the individual bag). The bag was transported to a boat where a $200 \mathrm{ml}$ subsample was removed and poured through a $200 \mu \mathrm{m}$ mesh filter. The bag sample was retained only if this subsample contained at least 5 eggs, i.e. there were an average of $25 \mathrm{eggs}^{-1}$ in the collecting bag. For each retained bag sample, a $1940 \mathrm{ml}$ subsample (the volume of readily available, plastic milk containers) was removed for further processing (Shapiro et al. 1994).

Eggs were filtered from all samples and subsamples 1.5 to 4 h after collection, lightly stained with rose bengal dye, and immediately examined under a dissecting microscope. Eggs were categorized as fertilized (FE) if they contained a perivitelline space and many cleaved cells, and were buoyant. Eggs were called unfertilized (UFE) if they contained no cleaved cells and were either positively buoyant with a perivitelline space or negatively buoyant without a perivitelline space.

Comparing FRs from net and bag samples. FRs of eggs collected with early bag, late bag, and net were compared by taking the 3 types of samples on the same day from the same spawning sites in the field. At 7 sites with pair-spawning TP males, all samples $(\mathrm{N}=12$ to 46 spawns male ${ }^{-1}$ for 7 males) came from the same male with different females. For group-spawning sites, the samples within a day came from different females spawning with different subsets of IP males. Samples were taken from group- and pair-spawning sites at 2 reefs, named ' 6 ' and ' 13 ' in Teague Bay.

Experimental tests of hypotheses. (1) Percentage of unfertilized eggs that were negatively buoyant: This percentage was compared among samples collected with the net $(N=120)$, with early bags $(N=222)$, and with late bags ( $N=113)$, for data from all pair spawns and group spawns on all collecting days 
(2) Influence of exposure of eggs to seawater and sperm prior to netting or $10 \mathrm{~s}$ after netting: In part 1 of this experiment, eggs obtained from females were netted prior to exposure to sperm. Eggs were squeezed from a ripe female, soon after capture in the field, into 100 to $150 \mathrm{ml}$ seawater and the egg sample was divided in half into 2 containers. To the first container, 0.2 to $0.5 \mathrm{ml}$ sperm squeezed from 2 males was added. This sample was left undisturbed for $120 \mathrm{~s}$ (the control sample). Eggs from the second container were immediately transferred to a brine shrimp net and the net was swept through seawater over the side of the field boat 10 times (yielding the experimental sample), a process requiring $<10 \mathrm{~s}$. The eggs were then flushed into a plastic container to which 0.2 to $0.5 \mathrm{ml}$ sperm squeezed from 2 males was added. The total volume was raised to $150 \mathrm{ml}$, and the sample was left undisturbed for $120 \mathrm{~s}$. After 2 to $3 \mathrm{~h}$, eggs from both samples were filtered out of the containers, stained with rose bengal dye and examined for fertilization. Thus, a control was always paired with an experimental sample $(\mathrm{N}=$ 14 replicates). Samples were only used if FR for the control equalled or exceeded $75 \%$, indicating that eggs were ripe and fertilizable (this procedure also applied to Part 2 below).

In part 2 of this experiment, eggs were netted $10 \mathrm{~s}$ after exposure to sperm and seawater. Eggs were squeezed from a ripe female into $100-150 \mathrm{ml}$ seawater. Sperm squeezed from 2 males were immediately added to the eggs. Eggs were then divided into 2 containers. The 'control' was left undisturbed for $120 \mathrm{~s}$ and then processed as above. Eggs from the second container were transferred to a brine shrimp net $10 \mathrm{~s}$ after the sperm were added and swept through seawater 10 times. Eggs were then flushed from the net into a plastic container and processed as in Part $1(\mathrm{~N}=11$ replicates). Thus, the entire experiment was designed to compare FRs for eggs swept with a net prior to exposure to sperm and $10 \mathrm{~s}$ after exposure.

(3) Influence of bag size on FR: This experiment was designed to test whether bag size influenced FR. Pair spawns from 1 site were collected alternately either with small $(65 \times 60 \mathrm{~cm}, 51 \mathrm{I}, \mathrm{N}=7$ samples $)$ and medium ( $65 \times 110 \mathrm{~cm}, 95 \mathrm{l}, \mathrm{N}=8$ ) bags (on $3 \mathrm{~d}$ ) or small $(\mathrm{N}=11)$ and large $(135 \times 185 \mathrm{~cm}, 750 \mathrm{l}, \mathrm{N}=10)$ bags (on 3 d). Paired comparisons of FRs were made on the same day collecting from the same male at the same site.

(4) Minimum sperm concentration and bag dilution: This experiment was designed to test whether the final sperm concentration of spawns collected in bags is high enough to fertilize eggs, an assumption required if bags artificially elevate FR via an effect on sperm concentration. In a $50 \mathrm{l} \mathrm{bag}$, the number of sperm released in pair spawns (range 0.3 to $21.4 \times 10^{6} \mathrm{sperm}$,
$\mathrm{N}=167$ pair spawns; Shapiro et al. 1994) would form a final sperm concentration of 6 to 428 sperm $\mathrm{ml}^{-1}$. For group spawns (range 40 to $2320 \times 10^{6}$ sperm, $N=$ 52 group spawns; Shapiro et al. 1994), the final concentration in a bag would be 800 to $46400 \mathrm{sperm} \mathrm{ml}^{-1}$. Artificial fertilization experiments were done to see if these concentrations could fertilize eggs.

Approximately $0.2 \mathrm{ml}$ of sperm was squeezed from a male; half of the sperm was immediately mixed in $4000 \mathrm{ml}$ of seawater and half in $1500 \mathrm{ml}$. Almost simultaneously, a much larger amount of sperm was squeezed from additional males into a third container of $1500 \mathrm{ml}$ seawater and eggs were squeezed from a ripe female into $100 \mathrm{ml}$ of seawater. The eggs were then divided into 3 roughly equal parts and added separately to the 3 containers of sperm. Gametes were mixed within $15 \mathrm{~s}$ of the moment they were stripped from fish, the maximum duration of competence to fertilize for most sperm (Petersen et al. 1992). Two minutes after sperm and eggs were mixed, the sample was transferred to a labelled plastic bottle. FR was measured, using procedures described above, and sperm were counted, using methods of Shapiro et al. (1994). This procedure was repeated with 8 sets of samples $(N=24)$. The variability in the number of sperm squeezed in the initial volumes of seawater yielded variable sperm concentrations against which FRs were plotted.

Statistical analysis. FRs were compared statistically either using non-parametric tests (Kruskal-Wallis 1 -way analysis of variance, Mann-Whitney $U$-test corrected for ties, Wilcoxon matched-pairs, signed-ranks test), when frequency distributions of arcsin-transformed FRs differed significantly from normality (Kolmogorov-Smirnov test), or using parametric tests ( $t$-test, paired $t$-tests, ANOVA) when arcsin-transformed FRs were normal or close to normal. Fisher's test of combined probability was used to combine results from disparate experiments. Reported mean and $95 \%$ confidence limits (CL) of FRs and percent damaged eggs were back-transformed from values calculated from arcsin-transformed data.

\section{RESULTS}

\section{Comparison of techniques}

When field collections with a minimum number of

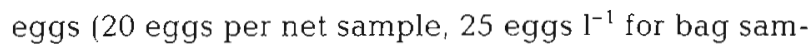
ples) were pooled, the average numbers of collected eggs differed significantly (ANOVA, $F_{2,453}=48.0, p<$ 0.0001 ) among the 3 collection techniques: early bag (mean $\pm \mathrm{SD}=72.6 \pm 43.4$ eggs per $1940 \mathrm{ml}$ sample, $\mathrm{N}=$ 222 samples), late bag $(59.7 \pm 39.7$ eggs per sample, 

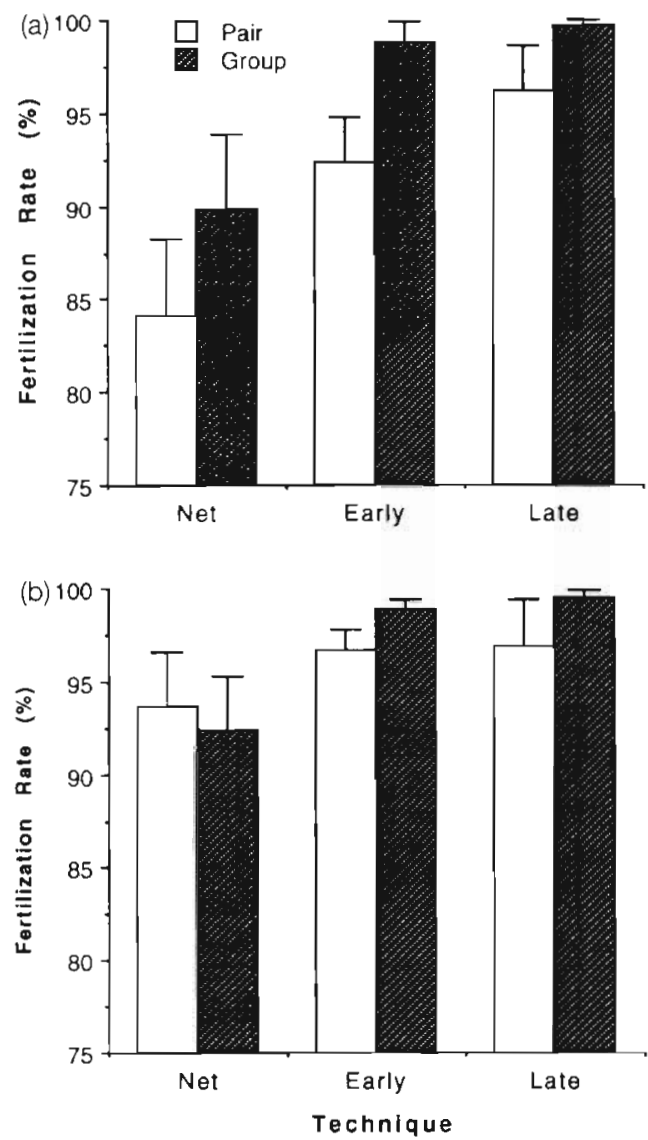

Fig. 1. Thalassoma bifasciatum. Mean (bar height) and $95 \%$ confidence limits (vertical line) for percent fertilization rates of eggs collected by net or in early or late bags from pair and group spawns on (a) reef 13 and (b) reef 6 . Reported values were back-transformed from arcsin-transformed data

$\mathrm{N}=113)$ and net $(37.2 \pm 110.3$ eggs per net sample, $\mathrm{N}=$ 121). On multiple range testing (Scheffé test), both early and late bag samples contained significantly more eggs than the net samples $(p<0.05)$, but early bag samples did not differ from late bag samples. Since the volume of a $1940 \mathrm{ml}$ subsample represented roughly 1.25 th of the total bag volume, overall the bags yielded many more eggs than did the net.

FRs varied significantly among the 3 techniques (early bag, late bag, and net) for each of 2 types of mating behavior on each of the 2 collection reefs (Fig. 1; Kruskal-Wallis 1-way ANOVA, \%FR vs collection method, $\mathrm{p}<0.001$ for pair and group spawns on both reefs). In each case, FRs fell into a consistent order: net < early bag < late bag, with the net FRs significantly lower than FRs from either of the 2 bag techniques (Mann-Whitney $U$-test corrected for ties, net vs early bag: $z$ ranged from -3.1 to $-5.5, p<0.0001$ for each reef-mating type combination; net vs late bag: $z$ ranged from -4.1 to $-5.5, p<0.0001$, for each reef- mating type combination). FRs from early bags were significantly lower than FRs from late bags for pair spawns on both reefs (reef 13: $z=-2.01, p=0.04$; reef $6: z=-2.2, p=0.02$ ). FRs from early bags tended to be lower than FRs from late bags for group spawns on both reefs (reef 13: $z=-1.73, p=0.08$; reef $6: z=-1.61$, $p=0.10$ ). In general, FRs from early bags were significantly lower than those from late bags (Fisher's combined probability test, $\mathrm{p}<0.005)$. Overall, mean FRs in the net were 3.2 to $12.1 \%$ lower than with the late bag and 3.0 to $8.9 \%$ lower than with the early bag.

\section{Tests of hypotheses}

When data from all pair spawns and group spawns were pooled from both reefs, the proportion of unfertilized eggs (UFE) that were negatively buoyant (no. sinking UFE/total UFE) was much higher (Fig. 2) in net samples $(N=120)$ than in either early bag $(N=222)$ or late bag $\left(\mathrm{N}=113\right.$ ) samples (ANOVA: $F_{2,455}=55.5, \mathrm{p}<$ 0.0001 ). In multiple-range comparisons, the proportion of negatively buoyant UFE was significantly higher in net samples than in both types of bag samples (Scheffé test, $p<0.05$ ), but early bags did not differ significantly from late bags. Thus, the net influenced properties of the eggs affecting buoyancy.

In experiments on the relation between netting and exposure of eggs to sperm, FRs were significantly lower (Wilcoxon matched-pairs, signed-rank test, $z=$ $-3.3, p=0.0001, N=14$ ) when eggs were swept with a net prior to exposure to sperm than in the control,

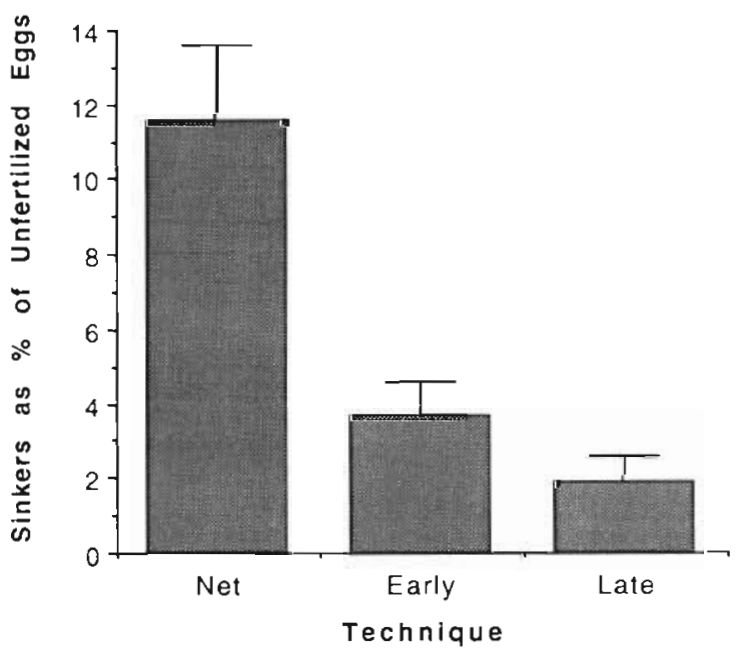

Fig. 2. Thalassoma bifasciatum. Mean (bar height) and $95 \%$ confidence limits (vertical line) for unfertilized eggs (UFE) that were negatively buoyant (sinkers) as a percentage of total UFE in samples collected by net or in early and late bags. Data pooled from reefs 13 and 6 . Reported values were backtransformed from arcsin-transformed data 


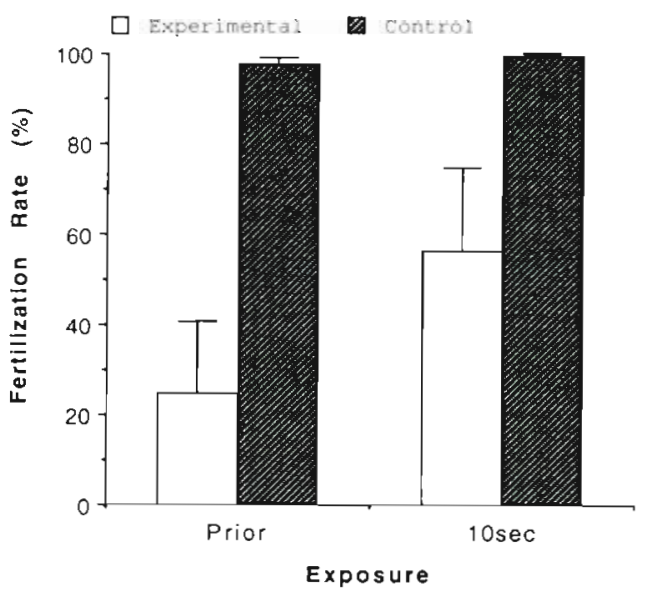

Fig. 3. Thalassoma bifasciatum. Mean (bar height) and $95 \%$ confidence limits (vertical line) for percent fertilization rates of eggs swept with a net prior (left set of bars) to exposure to sperm (experimental) or not swept with a net at all (control), and of eggs swept with a net $10 \mathrm{~s}$ (right set of bars) after exposure to sperm (experimental) or not swept at all (control). Reported values were back-transformed from arcsin-transformed data

when they were not swept with a net at all (Fig. 3). Furthermore, the percentage of net-swept, unfertilized eggs that were negatively buoyant was much higher $(\bar{X}=41.0 \%, C L=19.4$ to $64.6 \%)$ than in the control $(\bar{x}=$ $0.6 \%, C L=0.1$ to $1.5 \%$ ). When eggs were swept with a net $10 \mathrm{~s}$ after exposure to sperm, FR was also significantly lower (Wilcoxon, $z=-2.9, \mathrm{p}=0.003, \mathrm{~N}=11$ ) than the control (Fig. 3) and many more unfertilized eggs were negatively buoyant $(\bar{x}=6.8 \%, C L=0.9$ to $17.7 \%)$ than in the control $(\bar{x}=0.0 \%, C L=0.0$ to $0.2 \%)$. In other words, mean FR increased significantly from 25 to $56 \%$ when the temporal relation between exposure to sperm and netting changed from netting the eggs before exposure to netting them $10 \mathrm{~s}$ after exposure. Similarly, the percentage of unfertilized eggs that were negatively buoyant declined as exposure time increased prior to netting.

Although not formally part of this experiment, FRs from natural pair spawns $(\bar{x}=94.8 \%, C L=90.7$ to $97.8 \%, N=28)$ and group spawns $(\bar{x}=98.3 \%, C L=$ 97.1 to $99.2 \%, N=26$ ) collected with a net $30 \mathrm{~s}$ after spawning, on the same reef from which experimental males and females had been caught, were significantly higher than experimental FRs when eggs were swept before, and $10 \mathrm{~s}$ after, exposure of eggs to sperm (ANOVA, $F=91.82, \mathrm{p}=0.0001$ ), with Fisher's PLSD and Scheffé $F$-test (multiple range comparison tests) showing significant $(p<0.05)$ differences in all pairwise comparisons. These comparisons suggest that the negative effects of the net may continue to diminish for at least $30 \mathrm{~s}$ after exposure to sperm, as was found in an earlier field study (Petersen et al. 1992).

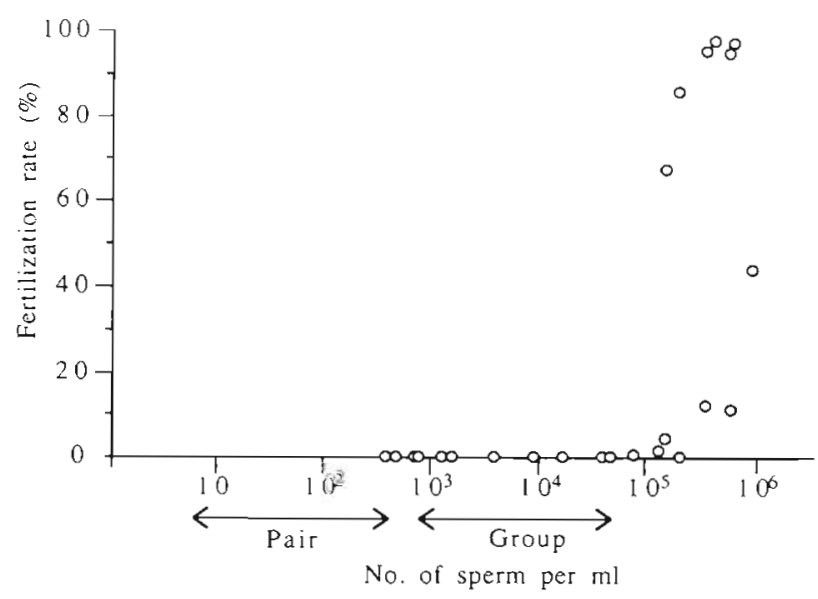

Fig. 4. Thalassoma bifasciatum. Fertilization rate (percent fertilized) of eggs in artificial fertilization experiments with various concentrations of sperm. The arrows span the range of calculated, final sperm cuncentration when the number of sperm released in natural pair and group spawns are fully dispersed in a collecting bag

In comparisons of $\mathrm{FR}$ from different sizes of bags, $\mathrm{FR}$ did not differ significantly $(t=0.85)$ between small $(\bar{X}=$ $99.4 \%, C L=97.8$ to $100.0 \%, N=7$ ) and medium bags $(\vec{x}=98.5 \%, C L=95.2$ to $99.9 \%, N=8)$. FR did differ significantly $(t=3.52, \mathrm{p}=0.002)$ between small $(\bar{x}=$ $85.9 \%, C L=83.1$ to $85.5 \%, N=11)$ and large bags $(\bar{x}=$ $97.1 \%, \mathrm{CL}=93.7$ to $99.2 \%, \mathrm{~N}=10$ ), but the direction of difference was opposite to that expected if the bag elevated $\mathrm{FR}$ by maintaining artificially high sperm concentrations: FR was higher in the large than in the small bag.

In the experiment examining the minimum concentration of sperm needed to initiate fertilization, FR remained zero for all sperm concentrations below $10^{5}$ sperm $\mathrm{ml}^{-1}$ (Fig. 4). FR first became greater than zero when the concentration exceeded what the average concentration would have been in a bag containing twice the largest number of sperm ever collected in a group spawn.

\section{Pair versus group spawns}

For reef 13 , FRs of group spawns were significantly higher than FRs of pair spawns for all 3 sampling techniques (Fig. 1 ; Mann-Whitney $U$-test, corrected for ties; early bag: $z=-4.1, \mathrm{p}<0.0001$; late bag: $z=-3.4, \mathrm{p}<$ 0.001 , net: $z=-2.3, p=0.01$ ). For reef 6 , FRs of group spawns were significantly higher for early bag samples (Fig. $1 ; z=-1.9, p=0.05)$, but not for late bag $(z=-1.2$, $p=0.23)$ or net samples $(z=-1.3, p=0.18)$, although the trend was in the same direction for late bag samples. FRs of some pair and some group spawns were 
Table 1. Thalassoma bifasciatum. Mean fertilization rates (\%FR), 95\% confidence limits (CL) and sample sizes (N) for pair spawns by individually identified (ID), terminal-phase males and for group spawns on reefs 13 and 6 . All samples were collected with the early bag technique

\begin{tabular}{|rccccc|}
\hline Reef & $\begin{array}{c}\text { Male } \\
\text { ID }\end{array}$ & $\begin{array}{c}\text { Spawning } \\
\text { type }\end{array}$ & $\begin{array}{c}\text { Mean } \\
\% \mathrm{FR}\end{array}$ & $\begin{array}{c}95 \% \\
\mathrm{CL}\end{array}$ & $\mathrm{N}$ \\
\hline 13 & 13E1 & Pair & 94.2 & $90.3-98.1$ & 12 \\
13 & $13 \mathrm{D} 1$ & Pair & 90.5 & $85.8-93.2$ & 30 \\
13 & $13 \mathrm{~A} 1$ & Pair & 86.6 & $81.8-91.4$ & 35 \\
13 & & Group & 98.8 & $97.6-99.7$ & 25 \\
6 & 1 & Pair & 96.0 & $94.2-97.8$ & 46 \\
6 & 3 & Pair & 95.1 & $91.2-99.0$ & 10 \\
6 & 4 & Pair & 99.2 & $98.5-99.9$ & 10 \\
6 & 5 & Pair & 98.4 & $97.4-99.4$ & 17 \\
6 & & Group & 98.9 & $98.4-99.4$ & 33 \\
\hline
\end{tabular}

$100 \%$ in both bag techniques, but pair spawns had higher variation in FR than did group spawns in both types of bag samples for both reefs (Fig. $1 ; F=2.86$ and $3.28, p<0.01$ for early and late bag samples, respectively, on reef $13 ; F=13.80$ and $87.11, p<0.001$ for early and late samples, respectively, on reef 6 ).

The difference between reef 13 and reef 6 in pair versus group-spawn comparisons was reflected in the FRs of pair spawns by individual males on these 2 reefs. All 3 individual males on reef 13 had mean FRs that were substantially below the mean FR of group spawns (Table 1), while the 4 males on reef 6 each had mean FRs that were similar to FRs of group spawns on that reef (Table 1).

\section{DISCUSSION}

\section{Comparison of techniques}

Eggs collected by net consistently had significantly lower FRs than eggs collected in bags. The magnitude of the difference in FR varied: differences between net and bag mean FRs for our 2 reefs ranged from 3 to $13 \%$, depending on the reef and whether the bag was early or late. Thus, the effect of the collection technique was considerable. The decrease in FR when using nets appears to be a general result: it occurred not only in the brine-shrimp net reported here, but also in a hand-held plankton net made of soft nylon, with mesh size $230 \mu \mathrm{m}$ and small cod-end collecting bottle, and in a stationary plankton net of mesh size $202 \mu \mathrm{m}$, length $150 \mathrm{~cm}$, and cod-end collecting bottle fixed 3 to $4 \mathrm{~m}$ downcurrent from the spawning site (Yoshikawa 1992).

High FR in bags was not the result of artificially high sperm concentrations persisting for longer in the bags than in nature. FRs were not higher in small than in large bags, as this hypothesis would predict. Furthermore, by the time sperm collected from a spawn had dispersed throughout the collecting bag, the calculated sperm concentration in the bag was substantially lower than the minimum of $10^{5}$ sperm $\mathrm{ml}^{-1}$ needed to initiate fertilization.

On the contrary, the evidence supported the hypothesis that nets interfere with properties of the eggs important to fertilization. In our samples from natural spawns, much higher proportions of unfertilized eggs were negatively buoyant when collected by net than when collected by bag. These proportions declined, and FRs increased, the longer the experimental delay between contact of the egg with seawater and sperm and the moment of netting (cf. Petersen et al. 1992). We suspect that netting causes physical changes in the egg membrane that interferes with the egg's ability to maintain its osmolarity, to become viably fertilized and to continue development for 2 to $4 \mathrm{~h}$ after contact with sperm.

Initially, we categorized negatively buoyant, unfertilized eggs as 'damaged', and positively buoyant, unfertilized eggs as 'normal but unfertilized'. In an effort to salvage the net technique, we estimated FR only on 'undamaged', positively buoyant eggs. The result was an elevation of $\mathrm{FR}$ to levels slightly above those seen in eggs collected with the bag. However, since normal, unfertilized eggs progress with time from being positively to negatively buoyant, this procedure artifactually eliminated an unknown proportion of normally unfertilized eggs from our estimates (cf. Markle \& Waiwood 1985). Consequently, we have chosen here not to use this modified counting technique, which overestimates FR, although net samples using this approach significantly covary with bag samples (Petersen unpubl. data).

Eggs collected by bag $30 \mathrm{~s}$ after gamete release are probably the most accurate measure of FR. These collections yield FRs consistently close to $100 \%$ for group spawns. Pair spawns collected with the same technique also had consistently higher FRs than did pair spawns collected with the other 2 techniques. A $30 \mathrm{~s}$ delay prior to collection leaves eggs and sperm undisturbed for a period longer than the viable competence of sperm (Petersen et al. 1992) and of sufficient duration for eggs to harden and become relatively resistant to collection damage.

We do not know the mechanism by which collection of eggs by bag 3 to $4 \mathrm{~s}$ after spawning produces lower FRs than delaying the collection to $30 \mathrm{~s}$. The decline may result from a disturbance of normal diffusive mixing attendant upon early incorporation of eggs and sperm within the bag. If so, then the reduction in FR in early bag samples, which disappeared in much larger 
bags, may be sensitive to large changes in bag volume. In this species, the effect of using an early bag is minimal (Table 1; means of 0.2 to $3.8 \%$ reduction in $F R$ compared with late bag samples), and early bags yield additional information on sperm number and fecundity of a spawn not available with the other methods.

The attraction of using a net is that it can be done by 1 person in the water and requires minimum manipulation of the sample. The bag technique requires an additional person in a boat to remove and process subsamples. Both techniques collect sufficient eggs to permit reasonable estimates of FRs, although the bag generally collects many more eggs than the net. Both methods generate a fair number of 'missed' collections, when no or very few eggs are collected from the spawn, especially when the collector is inexperienced. Missed collections are particularly prevalent in late bag samples because the collector's estimate of the location of the gamete cloud, where the sample will be taken, is easily mistaken. An advantage to the bag technique, if employed within several seconds of gamete release, is that it simultaneously collects both eggs and sperm, inereby permitting examination of a wide range of issues concerning fertilization dynamics and sperm allocation strategy (Shapiro et al. 1994, Warner et al. 1995, Marconato \& Shapiro 1996, Shapiro \& Giraldeau 1996).

The disadvantages of the net technique, namely that it seriously underestimates FR, when all eggs are counted, and introduces error into the data, when negatively bouyant eggs are not counted, outweigh the advantage of simplicity of the method. Consequently, in spite of 2 previous studies employing netting (Petersen 1991, Petersen et al. 1992), we do not recommend use of net techniques for estimates of FR unless it is demonstrated that such a technique does not artificially lower FR for a particular species or a particular type of net. Net collections from a wide range of pelagically spawning species have revealed egg damage from nets, ranging from less damage than in Thalassoma bifasciatum (species of Halichoeres and Serranus) to catastrophic damage (in Bodianus rufus; C. W. Petersen \& D. Levitan unpubl, data). Unless a study requires the highest degree of accuracy of FR, when the late bag technique would be appropriate, the early bag technique probably represents the best combination of reliability of estimates, ease of obtaining usable samples, and quantity of information.

\section{Pair versus group spawns}

The most reliable estimates for comparing FRs between pair spawns and group spawns are derived from bag samples. On both study reefs, FRs of pair spawns were significantly lower than FRs of group spawns when data were based on early bag samples taken 3 to $4 \mathrm{~s}$ after spawning. FRs of eggs collected in late bag samples $30 \mathrm{~s}$ after spawning were significantly lower for pair than for group spawns on 1 of our 2 reefs and tended to be lower on the other reef. The magnitude of the difference between pair-spawning mean FR and group-spawning mean FR was 2.2 to $6.4 \%$ for early bag samples and 2.6 to $3.5 \%$ for late bag samples.

In a population on the southwest coast of Puerto Rico (Yoshikawa 1992), when eggs were collected with the same early bag technique as in our study, FRs were also significantly lower in pair $(\bar{x}=89.4 \%, \mathrm{~N}=167)$ than in group spawns $(\bar{X}=98.4 \%, N=52 ; \mathrm{p}=$ 0.0001 , Mann-Whitney $U$-test). We suspect that a previous report of no significant difference in FRs between pair and group spawns resulted from a combination of smaller sample sizes and the increased variance and lower FRs contributed by egg damage from the use of the netting technique (Petersen et al 1992). In our results, the net technique did reflect the significantly higher FR of group spawns on reef 13 .

Thus, in general, group spawns fertilize larger proportions of a female's eggs than do pair spawns. Although the magnitude of the difference may change from reef to reef (from a non-significant difference of $2.6 \%$ to a significant difference of $3.5 \%$ on our 2 reefs, respectively, with late bag samples), the direction of the difference does not change. Combining our data with the results from Puerto Rico, we conclude that females spawning in pairs will, on average, have lower fertilization success than females spawning in groups.

Nevertheless, as the data for individual males on reef 6 indicate, individual males may produce fertilization rates that are non-significantly lower than group spawns on the same reef. Fertilization rates are higher in pair spawns in which the male has released larger numbers of sperm, and sperm release increases with declining mating frequency by the male (Warner et al. 1995). Differences in mating rates between the sampled males on reef 6 and those on reef 13 might explain the variation in results of pair- versus group-spawn comparisons on these reefs. Thus, for males with low mating rates, FRs in pair spawns may be as high as in group spawns.

On intermediate sized and large reefs, females spawn both in pairs and in groups (Warner \& Hoffman 1980, Hensley et al. 1994), even when FRs for those pair spawns are significantly lower than for group spawns on the same reef, as our data indicate. Why do females mate in pairs at all when they could achieve higher FRs more reliably by spawning exclusively in groups? Compensation may lie in survival or reproduction, and we can speculate on mechanisms which might operate in both of these processes 


\section{Survival}

There is evidence that pair-mating sites are not situated more advantageously than group-spawning sites, such that the disadvantages of a lower FR would be offset by higher post-spawning survivorship of young (Appeldoorn et al. 1994, Hensley et al. 1994). Groupspawning sites in fact tend to be at the extreme downcurrent edge of reefs (Warner \& Hoffman 1980, Warner $1984 \mathrm{~b}$ ), which might, if anything, minimize the time spent by eggs near reef-based egg predators (Hensley et al. 1994).

However, 1 possible advantage to mating in pairs with TP males may be in the survival of the female herself. Most of the predation we have witnessed in this species has occurred at group-mating sites (pers. obs.). While the large numbers of individuals at group sites may lessen the per capita risk of predation, such sites may still be dangerous places if predators focus their attention on less-agile, gravid females. At pair-mating sites, a brightly colored TP male engages in intense courtship of females, displaying conspicuous behavior in the water column at the site of mating. If such behaviors are, in fact, a demonstration of present safety from transient predators (Warner 1987), there may be some compensating advantage for females to mate at such sites. While there do not appear to be differences in growth or reproductive output between pair-mating and group-mating females (Warner 1985), we stress that we have no evidence for differences in survival at this time.

\section{Reproduction}

It is possible that persistent mating at a pairspawning site could improve the chance that a female, after sex change, might occupy that site following the loss of the previously resident male. Since territorial pair-spawning males have very high expected reproductive success (Warner 1984a), this could compensate for losses in FR as a female. However, females spend weeks to months as roving non-territorial TP males after sex change on large reefs (Hoffman et al. 1985), and ownership of a vacant territory appears to be decided on the basis of relative size among several contenders (Warner \& Schultz 1992). Thus, while we cannot eliminate the possibility of an eventual reproductive advantage for females engaging in pair spawning, it will be difficult to estimate its effect.

Acknowledgements. We thank the staff of the field station of the Department of Marine Sciences, University of Puerto Rico, in La Parguera for logistical support, and K. Asoh, C. Barrett, M. Berard, D. Fitch, C. Gerstner, J. Hagopian, T Knight, O. Kopecny, M. Obedzinski, M. Peharda, M. B. Rasotto, M.
Sheehy, E. Stevens, D. Sward, S. Swearer, M. Talkovic, V Vredenburg, J. Wilson and L. Wooninck for valuable field assistance. Work was supported by NSF grants RII8610677 and OCE-9206182, and a fellowship from CNR of Italy to A.M.

\section{LITERATURE CITED}

Appeldoorn RS, Hensley DA, Shapiro DY (1988) The use of various tracers in assessing the fate of pelagic eggs spawned by coral reef fishes. In: Proc 6th Int Symp Coral Reef 2:619-624

Appeldoorn RS, Hensley DA, Shapiro DY, Kioroglou S, Sanderson BG (1994) Egg dispersal in a Caribbean reef fish, Thalassoma bifasciatum. Il. Dispersal off the reef platform. Bull Mar Sci 54:271-280

Feddern HA (1965) The spawning, growth, and general behavior of the bluehead wrasse, Thalassoma bifasciatum (Pisces: Labridae). Bull Mar Sci 15:896-941

Hemple G (1979) Early life history of marine fish: the egg stage. Washington Sea Grant Public, Seattle

Hensley DA, Appeldoorn RS, Shapiro DY, Ray M, Turingan RG (1994) Egg dispersal in a Caribbean coral reef fish, Thalassoma bifasciatum. I. Dispersal over the reef platform. Bull Mar Sci 54:256-270

Hoffman SG, Schildhauer MP, Warner RR (1985) The costs of changing sex and the ontogeny of males under contest competition for mates. Evolution 39:915-927

Lasker HR, Stewart KM (1993) Gamete dilution and fertilization success among broadcast spawning octocorals. In: Proc 7 th Int Symp Coral Reef, University of Guam, p $476-483$

Levitan DR (1991) Influence of body size and population density on fertilization success and reproductive output in a free-spawning invertebrate. Biol Bull (Woods Hole) 181: 261-268

Levitan DR (1993) The importance of sperm limitation to the evolution of egg size in marine invertebrates. Am Nat 141: $517-536$

Levitan DR, Sewell MA, Chia FS (1991) How distribution and abundance influence fertilization success in the sea urchin Strongylocentrotus franciscanus. Ecology 73:248-254

Marconato A, Shapiro DY (1996) Sperm allocation, sperm production and fertilization rates in the bucktooth parrotfísh. Anim Behav 52:971-980

Markle DG, Waiwood KG (1985) Fertilization failure in gadids: aspects of its measurement. J Northwest Atl Fish Sci 6:87-93

Pennington JT (1985) The ecology of fertilization of echinoid eggs: the consequences of sperm dilution, adult aggregation, and synchronous spawning. Biol Bull (Woods Hole) 169:417-430

Petersen CW (1991) Variation in fertilization rate in the tropical reef fish, Halichoeres bivattatus; correlates and implications. Biol Bull (Woods Hole) 181:232-237

Petersen CW, Warner RR, Cohen S, Hess HC, Sewell AT (1992) Variable pelagic fertilization success: implications for mate choice and spatial patterns of mating. Ecology 73: $391-401$

Pommeranz T (1974) Resistance of plaice eggs to mechanical stress and light. In: Blaxter JHS (ed) The early life history of fish. Springer-Verlag, Heidelberg, p 397-416

Randall JE (1968) Caribbean reef fishes. TFH Publications, Jersey City, NJ

Reinboth R (1973) Dualistic reproductive behavior in the protogynous wrasse Thalassoma bifasciatum and some obser- 
vations on its day-night changeover. Helgoländer Wiss Meeresunters 24:174-191

Shapiro DY, Giraldeau LA (1996) Mating tactics in external fertilizers when sperm is limited. Behav Ecol 7:19-23

Shapiro DY, Marconato A, Yoshikawa T (1994) Sperm economy in a coral reef fish. Ecology 75:1334-1344

Shapiro DY, Rasotto MB (1993) Sex differentiation and gonadal development in the diandric protogynous wrasse, Thalassoma bifasciatum. J Zool (Lond) 230:231-245

Thresher RE (1984) Reproduction in reef fishes. TFH Publications, Neptune City, NJ

Warner RR (1984a) Deferred reproduction as a response to sexual selection in a coral reef fish: a test of the life historical consequences. Evolution 38:148-162

Warner RR (1984b) Mating behavior and hermaphroditism in coral reef fishes. Am Sci 72:128-136

Warner RR (1985) Alternative mating behaviors in a coral reef fish: a life-history analysis. In: Gabrie C, Salvat B (eds) Proc 5th Int Coral Reef Congr, Vol 4. Antenne MuseumEphe, Moorea, p 145-150

Warner RR (1987) Female choice of sites versus mates in a

Editorial responsibility: Otto Kinne (Editor),

Oldendorf/Luhe, Germany coral reef fish, Thalassoma bifasciatum. Anim Behav 35 $1470-1478$

Warner RR, Hoffman SG (1980) Local population size as a determinant of mating system and sexual composition in two tropical marine fishes (Thalassoma spp.). Evolution 34 $508-518$

Warner RR, Robertson DR (1978) Sexual patterns in the labroid fishes of the western Caribbean: I. The wrasses (Labridae). Smithson Contr Zool 254:1-27

Warner RR, Robertson DR, Leigh EG (1975) Sex change and sexual selection. Science 190:633-638

Warner RR, Schultz ET (1992) Sexual selection and male characteristics in the bluehead wrasse. Thalassoma bifasciatum: mating site acquisition, mating site defense and female choice. Evolution 46:1421-1442

Warner RR, Shapiro DY, Marconato A, Petersen CW (1995) Sexual conflict: males with highest mating success convey the lowest fertilization benefits to females. Proc R Soc Lond Ser B 262:135-139

Yoshikawa T (1992) Efficient sperm use in a coral reef fish MSc thesis, University of Puerto Rico, Mayagüez

Submitted: October 7, 1996; Accepted: October 15, 1997

Proofs received from author(s): December 22, 1997 